\title{
SOBRE A POBREZA DA EXPERIÊNCIA: UM DIÁLOGO ENTRE WALTER BENJAMIN E HANNAH ARENDT SOBRE A PERDA DA TRADIÇÃO
}

\author{
Francisco Jameli Oliveira Reinaldo \\ Ricardo George de Araújo Silva
}

\begin{abstract}
RESUMO
Este artigo propõe um diálogo entre Walter Benjamin e Hannah Arendt a respeito da perda da tradição, que em Benjamin implica na pobreza de experiência. Para tanto, é preciso termos em mente o pano de fundo das experiências políticas do século XX das duas grandes Guerras. Diante delas, a destruição é vista como uma categoria decisiva. É à luz da perda da tradição, do campo de ruínas, que o filósofo tem de partir, para encontrar, em meio ao amontoado de destroços, as pérolas da tradição.
\end{abstract}

Palavras-chave: Experiência. Tradição. Benjamin. Arendt.

\section{ABOUT POVERTY OF EXPERIENCE: A DIALOGUE BETWEEN WALTER BENJAMIN AND HANNAH ARENDT ABOUT THE LOSS OF TRADITION}

\begin{abstract}
This article proposes a dialogue between Walter Benjamin and Hannah Arendt about the loss of tradition that in Benjamin implies the povertyof experience. To do so, we need to have in mind the background of politics experience of century $X X$ of two big Wars. Front him destruction is sight as a decisive political category. It is the light of the loss of tradition, the field of ruins, the philosopher must begin from to find, in the middle of jumble of debris, the pearls of tradition.
\end{abstract}

Keywords: Experience. Tradition. Benjamin. Arendt.

Mestre em Filosofia pela Universidade Estadual do Ceará - UECE. Brasileiro, residente em Massapê-CE. E-mail: dulitle@hotmail.com

Doutor em Filosofia pela Universidade Federal do Ceará - UFC. Professor da Universidade

Estadual Vale do Acaraú - UEVA. Brasileiro, residente em Fortaleza-CE. E-mail: 
Ao nos debruçarmos sobre o pensamento benjaminiano, uma primeira característica que salta aos olhos é o seu modus philisophandi: é ele um pensador, em vários aspectos, sui generis. Na verdade, a filosofia benjaminiana é muitas vezes definida como "uma filosofia dirigida contra a filosofia" (BENJAMIN, apud. BENJAMIN e OSBORNE, 1997). Walter Benjamin é um nome que não cabe dentro do quadro filosófico tradicional por uma série de motivos que Arendt, no seu livro dedicado aos homens em tempos sombrios, os tempos de confusão política que conduziram às duas grandes guerras, claramente explicitou. Para ela, se quisermos classificar o pensamento benjaminiano, só o conseguiremos fazê-lo negativamente. Diz Arendt:

[...] Para descrever adequadamente sua obra e seu perfil de autor dentro de nosso quadro habitual de referências, seria preciso apresentar uma série imensa de declarações negativas, tais como: sua erudição era grande, mas não era um erudito; o assunto dos seus temas compreendia textos de interpretação, mas não era um filólogo; sentia-se muito atraído não pela religião, mas pela teologia e o tipo teológico de interpretação pelo qual o próprio texto é sagrado, mas não era teólogo, nem se interessava particularmente pela bíblia; era um escritor nato, mas sua maior ambição era produzir uma obra que consistisse inteiramente em citações; foi o primeiro alemão a traduzir Proust (juntamente com Franz Hessel) e St.-John Perse, e antes disso traduzia Quadros parisienses de Baudelaire, mas não era tradutor; resenhava livros e escreveu uma série de ensaios sobre autores vivos e mortos, mas não era um crítico literário; escreveu um livro sobre o barroco alemão e deixou um imenso estudo inacabado sobre o século XIX francês, mas não era historiador, literato ou o que for; tentarei mostrar que ele pensava poeticamente, mas não era poeta nem filósofo. (ARENDT, 2008a).

De fato, não se pode inserir Benjamin no quadro filosófico habitual. Nisso, não apenas Arendt, mas também Habermas está de acordo. Segundo ele, "Benjamin pertence àqueles autores inclassificáveis, cuja obra está predestinada a produzir efeitos heterogêneos" (HABERMAS, 1990). A polifonia do pensar quase poético, enigmático, por vezes, dificulta a apreensão imediata do pensamento do autor. Nossa hipótese é que a dificuldade de ambientação é característica, não apenas do pensador alemão, mas de nosso próprio tempo.

Mestre em Filosofia pela Universidade Estadual do Ceará - UECE. Brasileiro, residente em Massapê-CE. E-mail: dulitle@hotmail.com

Doutor em Filosofia pela Universidade Federal do Ceará - UFC. Professor da Universidade

Estadual Vale do Acaraú - UEVA. Brasileiro, residente em Fortaleza-CE. E-mail: 
Consoante Arendt, vivemos tempos sombrios. O que significa dizer que não há mais um "corrimão" interpretativo a que se possa apoiar com segurança, que olhamos o passado sem o fio de continuidade da tradição, que as mentes que, como Benjamin, clareiam esses tempos sombrios, são aquelas que melhor traduzem essa perplexidade.

Apesar disto, no entanto, não é preciso levar às últimas consequências a definição arendtiana do "homem de letras", do pensador que pensava poeticamente, mas não era poeta nem filósofo. Isto também não significa dizer que Arendt esteja equivocada, afinal, tanto ela quanto Benjamin não são filósofos à la Hegel, isto é, sistemáticos, tradicionais; ela própria se diz cientista política (Cf. ARENDT, 2008b) e ele é, por vezes, visto como crítico literário. Nos tempos sombrios, é preciso reinventar o significado do termo filósofo ${ }^{1}$.

Não obstante interpretações polissêmicas sobre a apreensão do pensamento benjaminiano, em uma coisa todos os pensadores que acima mencionamos estão de acordo: Walter Benjamin é, de fato, um autor sui generis. Sob os vários matizes, alguns deles evidenciados nas definições paradoxais de Arendt, que poderíamos utilizar, para corroborar nossa afirmação, um que especialmente ocupa boa parte da obra benjaminiana durante toda sua vida: 0 conceito de experiência. Por ele, poderemos estabelecer um diálogo entre 0 pensador alemão e Arendt a respeito da perda da tradição. É essa a nossa pretensão no presente texto.

O que a princípio parece uma categoria banal, prosaica, algo que está no discurso comum, não apenas sem interesse, mas em manifesta contradição com o universo conceitual da filosofia tradicional, que desde Platão define a experiência cotidiana como confusão e ilusão, que o filósofo deve abandonar,

\footnotetext{
1 A esse respeito, Löwy esclarece: "Era ele, antes de tudo, um crítico literário, um 'homem de letras' e não um filósofo, como pretendia Hannah Arendt? Na verdade, como Gershon Scholem, acredito que ele era um filósofo, mesmo que escrevia sobre arte ou literatura. O ponto de vista de Adorno é semelhante ao de Scholem, como explica em uma carta (inédita) a Hannah Arendt: 'A meu ver, o que define o significado de Benjamin para minha própria existência intelectual é evidente: a essência de seu pensamento enquanto pensamento filosófico. Jamais pude encarar sua obra a partir de outra perspectiva [...]"' (LÖWY, 2005).
}

Mestre em Filosofia pela Universidade Estadual do Ceará - UECE. Brasileiro, residente em Massapê-CE. E-mail: dulitle@hotmail.com

Doutor em Filosofia pela Universidade Federal do Ceará - UFC. Professor da Universidade Estadual Vale do Acaraú - UEVA. Brasileiro, residente em Fortaleza-CE. E-mail: 
em Benjamin assume uma importância primordial. É à luz do declínio da tradição, onde o arcabouço conceitual da filosofia tradicional não mais dá conta de apreender a realidade em sua multiplicidade e a experiência de totalidade, que fecha o mundo num grande sistema, não respondendo às perplexidades do mundo sempre fluido, que Benjamin advoga para a sua filosofia uma totalidade de experiência.

Essa mudança de ênfase é situada exatamente na inversão de valores entre a hierarquia ideia e fenômeno. Segundo Arendt, "o que desde o início fascinou Benjamin nunca foi uma ideia, foi sempre um fenômeno. 'O que parece paradoxal em tudo que é, com justiça, chamado de belo é o fato que apareça' (Schriften, vol. I, p. 349)" (ARENDT, 2008a).

É diante dessa perda da experiência que pretendemos aproximar Benjamin de Arendt. Essa aproximação dar-se-á pelo esclarecimento da perda da tradição, do obscurecimento de um passado que não tem mais autoridade sobre o presente. Esse reconhecimento do declínio da tradição é fruto de um longo e lento processo, mas que atinge os mais dramáticos matizes com a experiência de guerra - em Benjamin a primeira e em Arendt a última. Na guerra, a destruição se transforma no evento crucial.

Quando o quadro conceitual habitual não dá conta de compreender as perplexidades do tempo, quando a tradição se transforma num grande campo de ruínas, quando o passado não mais é capaz de iluminar o presente, é preciso ser sui generis e procurar caçar as pérolas - Benjamin - e encontrar o tesouro perdido - Arendt. É o próprio período de incertezas do século passado que exige de Benjamin e Arendt um modus philosophandi original. De posse destas questões, passemos à análise da quebra da tradição e a pobreza da experiência à luz do fenômeno da guerra.

\section{Sobre a pobreza da experiência e a quebra da tradição: um diálogo entre Benjamin e Arendt}

Mestre em Filosofia pela Universidade Estadual do Ceará - UECE. Brasileiro, residente em Massapê-CE. E-mail: dulitle@hotmail.com

Doutor em Filosofia pela Universidade Federal do Ceará - UFC. Professor da Universidade Estadual Vale do Acaraú - UEVA. Brasileiro, residente em Fortaleza-CE. E-mail: 
O pano de fundo das caóticas vivências políticas do século XX colocou em cheque a crença ingênua dos séculos anteriores no desenvolvimento ininterrupto das capacidades humanas. Sob o paradoxo da crescente elevação da técnica e a consequente miséria da destruição propiciada pela guerra, fica difícil acreditar no ideal de progresso, por esse viés. O século XX é frequentemente caracterizado como um período de tensões e incertezas. Para Giddens "a modernidade tem também um lado sombrio, que se tornou muito aparente no século atual" (GIDDENS, 1991, grifo nosso).

À luz das duas grandes guerras, do extermínio dos campos de concentração e da bomba atômica, a técnica revela sua natureza ambivalente. Intimamente relacionada ao desenvolvimento da técnica está a ânsia por instrumentalizar a natureza em função da busca por segurança. Tal busca, na verdade, revela, no âmago desta mesma técnica, um choque de forças, uma tensão entre segurança e perigo. O "lado sombrio" de nossa era guarda uma assustadora revelação: em alguns aspectos, a técnica parece ter vencido o homem. Ao refletir sobre o desenvolvimento do nazismo, Elias esclarece essa tensão:

Tal como a descoberta do fogo permitiu que o alimento fosse cozido, assim como a destruição de cabanas e casas pelas chamas; tal como a invenção da metalurgia acarretou grande progresso na agricultura e na guerra; tal como a energia atômica pôde ter um uso pacífico como fonte energética e ser uma arma terrível, também as invenções sociais são bifrontes. (ELIAS, 1997, grifo nosso).

Neste sentido, não é possível alçar uma compreensão clara do século passado sem enfrentar o tema da guerra, ocasião em que a tensão tornou-se mais explosiva; de fato, este é um tema caro tanto para Benjamin como para Arendt. Vale lembrar que Benjamin sequer viveu para presenciar o auge das inúmeras atrocidades provocadas na Segunda Guerra, atrocidades cujas maiores vítimas seriam os judeus de origem alemã, como era o caso do próprio Benjamin, de Arendt e tantos outros.

Se já em 1933, - e em textos anteriores, talvez mesmo imediatamente depois da Primeira Guerra mundial - Benjamin já refletia com clareza sobre os

Mestre em Filosofia pela Universidade Estadual do Ceará - UECE. Brasileiro, residente em Massapê-CE. E-mail: dulitle@hotmail.com

Doutor em Filosofia pela Universidade Federal do Ceará - UFC. Professor da Universidade Estadual Vale do Acaraú - UEVA. Brasileiro, residente em Fortaleza-CE. E-mail: 
impactos que a guerra causara, deixando "as ações da experiência em baixa" (BENJAMIN, 1994), o que diria ele da "fábrica de cadáveres" - no dizer de Arendt - que foram os campos de concentração na Alemanha nazista? Certamente Benjamin ficaria tão perplexo quanto Arendt. Há um forte indício disso quando ele reflete sobre a silenciosa ${ }^{2}$ experiência dos combatentes que voltaram da Primeira Guerra:

[...] nunca houve experiências mais radicalmente desmoralizadas que a experiência estratégica pela guerra de trincheiras, a experiência econômica pela inflação, a experiência do corpo pela fome, a experiência moral pelos governantes. Uma geração que ainda fora à escola num bonde puxado por cavalos viu-se abandonada, sem teto, numa paisagem diferente em tudo, exceto nas nuvens, e em cujo centro, num campo de forças de correntes e explosões destruidoras, estava o frágil e minúsculo corpo humano. (BENJAMIN, 1994 Grifo nosso).

A experiência dos combatentes é silenciosa, isto é, pobre em experiências comunicáveis, justamente porque a técnica criada pelo homem ultrapassa a dinâmica de suas próprias forças, expondo à crua nudez do "frágil e minúsculo corpo humano". Que biótipo de homem se permitiu diminuir por suas próprias forças criativas? Arendt o classifica como animal laborans, o homem dedicado às atividades vinculadas ao consumo.

$\mathrm{Na}$ descrição fenomenológica das atividades que compõem a condição humana, no livro homônimo, Arendt classifica o trabalho como a atividade

2 Erich M. Remarque soube corretamente transmitir este sentimento no romance anti-guerra Nada de novo no front, para muitos, visto como algum tipo de traição (Cf. ELIAS, 1997), ao remover a crosta de heroísmo, por vezes galvanizada nas expressões perplexas e desesperadoras de jovens despreparados, morrendo e matando-se aos montes, sem sequer ter consciência das motivações do conflito. O relato do protagonista, que se confunde com as experiências do próprio autor, quando presencia o sofrimento "inimigo", causado por ele, é ilustrativo: "Que horas atrozes! O estertor começa: como o ser humano morre lentamente. De uma coisa estou certo: ele não pode ser salvo. [...] esta esperança foi destruída, desfez-se diante dos seus gemidos. [...] À tarde, atinjo o limite dos pensamentos. A fome me devora: é tanta, que sinto vontade de chorar, não consigo lutar contra isto. Por várias vezes vou buscar mais água para o moribundo, e eu mesmo bebo também. Este é o primeiro homem que matei com minhas próprias mãos, e cuja morte, posso constatá-lo sem sombra de dúvida, foi obra minha. Kat, Kropp e Müller também já viram homens a quem mataram: isto acontece a muita gente, principalmente em combate corpo a corpo... Mas cada respiração arquejante corta o meu coração. Este ser que agoniza tem o tempo do seu lado, possui um punhal invisível, com que me fere: o tempo e meus pensamentos. Quanto não daria eu para que se salvasse! É duro ficar deitado aqui, sendo obrigado a ver e ouvi-lo." (REMARQUE, 1981).

Mestre em Filosofia pela Universidade Estadual do Ceará - UECE. Brasileiro, residente em

Massapê-CE. E-mail: dulitle@hotmail.com

Doutor em Filosofia pela Universidade Federal do Ceará - UFC. Professor da Universidade

Estadual Vale do Acaraú - UEVA. Brasileiro, residente em Fortaleza-CE. E-mail: 
empenhada no provimento da vida, no ciclo exaustivo do produzir e consumir, fruição que põe em risco a permanência do mundo, mundo natural, a Terra, e cultural, produto da inventividade humana. Há também o homo faber, o criador de coisas duráveis, como as obras de arte, arquitetura, pintura, escultura, etc. À diferença do animal laborans, o homo faber não consome os objetos que produz, mas usa. Há ainda o homem de ação, dedicado à preservação do espaço público em sua configuração política. Por que o animal laborans pode ser classificado como o homem diminuído por suas forças criativas?

Consoante Arendt, vivenciamos a vitória do animal laborans. Este considera a vida e os atributos a ela inerentes, como o trabalho, como valores absolutos. A permanência do mundo, obra do homo faber, e a preservação de um espaço público são sacrificadas em função da lógica do descartável. Consumimos não apenas os objetos de consumo, como o alimento cotidiano, mas também os de uso. Casa, mobílias, valores, tudo pode ser descartado conforme as conveniências do animal laborans.

Não faria sentido para os séculos anteriores um conflito que colocasse em risco igualmente a sobrevivência de vencedores e vencidos. Na Primeira Guerra e mais ainda na Segunda, com os campos de concentração e a bomba atômica, a lógica do descartável invadiu a própria técnica e, em consequência, os homens, classes específicas, como os judeus, também passaram a ser identificadas como seres supérfluos.

Com as vivências desmoralizadoras das guerras, a vitória do animal laborans tornou-se clara. Arendt vê, no início da modernidade, essa vitória. Antes disso ainda podíamos controlar nosso processo produtivo. A metáfora do homo faber é como a de um carpinteiro que ao confeccionar um móvel é senhor de todo o processo produtivo, sabe exatamente o que irá fazer. É possível vislumbrar o biótipo de animal laborans nas linhas de produção; o artífice, se é que se pode classificar deste modo, sequer tem domínio do que produz.

Para Arendt, ao refletir sobre a Segunda Guerra, o surgimento do totalitarismo marcou negativamente o mundo ocidental de tal maneira que rompeu, definitivamente, com a tradição de pensamento político ocidental. $\mathrm{O}$

Mestre em Filosofia pela Universidade Estadual do Ceará - UECE. Brasileiro, residente em Massapê-CE. E-mail: dulitle@hotmail.com

Doutor em Filosofia pela Universidade Federal do Ceará - UFC. Professor da Universidade

Estadual Vale do Acaraú - UEVA. Brasileiro, residente em Fortaleza-CE. E-mail: 
campo de concentração como paradigma da dominação total trouxe à luz a completa negação da individualidade humana. O novo homem que surge nos campos é tão descartável como qualquer outro objeto e tão insignificante como um bacilo. As câmaras de gás dão testemunho eloquente de que determinado tipo de gente, na compreensão do totalitarismo, não merece mais estima do que um inseto.

Neste sentido, as palavras de Benjamin, em 1933, refletindo sobre a Primeira grande Guerra, soam como um presságio: "uma nova forma de miséria surgiu com esse monstruoso desenvolvimento da técnica, sobrepondo-se ao homem" (BENJAMIN, 1994, grifo nosso). O monstruoso desenvolvimento da técnica e a concomitante experiência da destruição provocada na guerra, tendo justamente a técnica como mediação, põem-nos diante de um dilema: qual o valor de nossa técnica? "Qual o valor de todo o nosso patrimônio cultural, se a experiência não mais o vincula a nós?" (BENJAMIN, 1994). O animal laborans, preso ao metabolismo da vida, desconhece significado da técnica porque não vislumbra outros valores a não ser os que garantem a sobrevivência dos seus.

O animal laborans adequa-se perfeitamente às exigências efêmeras e instrumentais da nossa sociedade. O perpetrador dos grandes horrores do totalitarismo não é um sádico ou um maníaco, é o cidadão de bem, dócil cumpridor de tarefas. $O$ dente de engrenagem da maquinaria de destruição e morte do totalitarismo não precisa ser alguém que, como Hitler, tenha grandes convicções ideológicas, basta que obedeça inquestionavelmente às ordens do Líder em troca de salário e prestígio.

Sob o pano de fundo da guerra a destruição torna-se um evento decisivo para ambos. À luz dela, tanto Arendt quanto Benjamin veem com clareza o esfacelamento da tradição - como um tesouro perdido, no primeiro caso, e como um enorme campo de ruínas, no segundo. Como afirma Arendt no prefácio da obra Entre o passado e o futuro, o passado perdeu a capacidade de lançar luz sobre o presente, e nossa mente, carente de referências, vagueia nas trevas. São as referências que permitem nos situarmos corretamente no mundo, e a

Mestre em Filosofia pela Universidade Estadual do Ceará - UECE. Brasileiro, residente em Massapê-CE. E-mail: dulitle@hotmail.com

Doutor em Filosofia pela Universidade Federal do Ceará - UFC. Professor da Universidade Estadual Vale do Acaraú - UEVA. Brasileiro, residente em Fortaleza-CE. E-mail: 
perda da tradição, a perda de um passado que não tem mais autoridade, representa, em Arendt, essa ausência.

Do mesmo modo, a ausência de referências pode ser percebida no paradoxo benjaminiano da crescente produção cultural e a concomitante pobreza de experiência. A estética de guerra, como utilização antinatural das forças produtivas, "prova com suas devastações que a sociedade não estava suficientemente madura para fazer da técnica o seu órgão, e que a técnica não estava suficientemente avançada para controlar as forças elementares da sociedade" (BENJAMIN, 1994).

Ao refletir sobre o fenômeno da morte da narrativa, num ensaio sobre a obra de Nikolai Leskov, Benjamin reforça a ideia de que a perda da experiência está intimamente relacionada com a incapacidade humana de saber o que fazer com o rico patrimônio cultural, de não articular a riqueza das forças produtivas com a riqueza da própria experiência. A morte da arte de narrar pode ser vista como paradigma da perda de experiências comunicáveis. Pois o narrador, segundo Benjamin

[...] é um homem que sabe dar conselhos. Mas, se "dar conselhos" parece hoje algo antiquado, é porque as experiências estão deixando de ser comunicáveis. [...] O conselho tecido na substância viva da existência tem um nome: sabedoria. A arte de narrar está definhando porque a sabedoria - o lado épico da verdade - está em extinção. (BENJAMIN, 1994).

A perda da sabedoria transmitida pela narrativa representa justamente 0 estado flutuante do homem moderno: não há mais nada em que se apoiar e tudo é incerto. Benjamin ambienta a morte da narrativa no florescimento do que ele denomina de cultura de vidro, que não permite que nada se fixe, que elimina 0 mistério, a aura.

O definhamento da arte de narrar e a concomitante perda da experiência são frutos de um longo e lento processo que Jeanne Marie Gagnebin, no prefácio do primeiro volume sobre a coletânea de ensaios de Walter Benjamin intitulada Magia e técnica, arte e política, sabiamente caracterizou:

Mestre em Filosofia pela Universidade Estadual do Ceará - UECE. Brasileiro, residente em Massapê-CE. E-mail: dulitle@hotmail.com

Doutor em Filosofia pela Universidade Federal do Ceará - UFC. Professor da Universidade Estadual Vale do Acaraú - UEVA. Brasileiro, residente em Fortaleza-CE. E-mail: 
a) a experiência transmitida pelo relato deve ser comum ao narrador e ao ouvinte. Pressupõe, portanto, uma comunidade de vida e de discurso que o rápido desenvolvimento do capitalismo, da técnica, sobretudo, destruiu. [...] b) Esse caráter de comunidade entre vida e palavra apoia-se ele próprio na organização pré-capitalista do trabalho, em especial na atividade artesanal. c) A comunidade da experiência funda a dimensão prática da narrativa tradicional. Aquele que conta transmite um saber, uma sapiência, que seus ouvintes podem receber com proveito. (GAGNEBIN, 1994).

Em certa medida, a cultura do descartável é inerente ao desenvolvimento instrumental do capitalismo. O ritmo acelerado ditado pela lógica do mundo capitalista não permite que nada se fixe. É precisamente essa fixidez, essa permanência, que a experiência exige para que a sabedoria seja comunicada. A pobreza de experiências comunicáveis é bem ilustrada no que Benjamin define como cultura de vidro. Diz ele: "não é por acaso que o vidro é um material tão duro e tão liso, no qual nada se fixa. É também um material frio e sóbrio. As coisas de vidro não têm nenhuma aura. $O$ vidro é em geral o inimigo do mistério" (BENJAMIN, 1994).

O alcance globalizante do capitalismo aboliu todas as fronteiras. A reivindicação de uma comunidade de vida e palavra é inviabilizada pela miscelânea de narrativas, superpostas pela homogeneização das convivências ${ }^{3}$.

Para Benjamin, lembra Peter Osborne, "imediatamente antes e depois da Primeira Guerra Mundial, a filosofia existente padecia de um empobrecimento das ideias de experiência e verdade" (OSBORNE, 1997). É sob o declínio das ideias de experiência e verdade que Benjamin reivindica para si uma filosofia que abrangesse a totalidade de experiências: totalidade de experiência, convém lembrar, e não experiência de totalidade. A experiência de totalidade, que prende

3 Isto não significa, evidentemente, que não existam grupos heterogêneos. Na verdade, o entrechoque destes caracteriza a nossa vivência cotidiana. Elias, citando um relato extraído do Time Magazine, de 27 de novembro de 1978, ilustra corretamente esse fenômeno: "Um homem sentado num ônibus que vai para o centro da cidade sofre todos os tormentos de um exame íntimo antes de oferecer o seu assento a uma senhora. O macho tem de aprender a avaliar uma mulher pela idade, educação e possivelmente a ferocidade do feminismo antes de abrir uma porta para ela: será que se sentiria ofendida com um gesto de cortesia? Isso favorece a ambiguidade: se um homem intencionalmente se recusa a abrir uma porta para uma mulher, está dando provas de ser sexualmente liberado? Ou é apenas um cretino mau-educado? (ELIAS, 1997).

Mestre em Filosofia pela Universidade Estadual do Ceará - UECE. Brasileiro, residente em

Massapê-CE. E-mail: dulitle@hotmail.com

Doutor em Filosofia pela Universidade Federal do Ceará - UFC. Professor da Universidade

Estadual Vale do Acaraú - UEVA. Brasileiro, residente em Fortaleza-CE. E-mail: 
o mundo num imobilismo sintético, não dá conta da multiplicidade do real. Não é mais possível elaborar uma filosofia nos moldes tradicionais, à maneira de Hegel e Platão. É neste sentido que a totalidade de experiência se faz necessária.

O desenvolvimento do pensamento de Benjamin é marcado por duas preocupações fundamentais e por duas preocupações transformadoras subsequentes. Em primeiro lugar, encontramos 0 anseio pela formulação filosófica de um conceito ampliado ou "total" de experiência (Erfahrung), uma "multiplicidade uniforme e contínua de conhecimento" que não excluiria de seu âmbito nenhum domínio, ainda que marginal, extravagante ou esotérico. Ao lado disso encontra-se um enfático conceito de verdade como um "reino das ideias que se apresenta por si mesmo" (sichdarstellendenldeenreiches), um "estado não-intencional do ser" (intentionsloses Sein), que preexiste a toda atividade constitutiva do intelecto. A terefa da filosofia passa assim a ser vista como "a apresentação (Darstellung) de ideias por meio do empírico" mediante a construção de configurações ou constelações de "elementos concretos no conceito" (dinglicher Elemente im Begriff) que, por seu papel mediador, irão salvar (retten) os fenômenos da experiência para a experiência da verdade. (OSBORNE, 1997).

É claro que essa totalidade de experiência não é um fenômeno que deve desconsiderar a experiência da destruição, sobretudo no século $X X$. Do contrário, a destruição é precisamente o ponto de partida para uma experiência de verdade. Daí o paradoxo: "'O caráter destrutivo' é fundado no pressuposto de que há momentos críticos em que somente mediante a 'destruição' a ' humanidade... pode dar prova de sua têmpera"” (OSBORNE, 1997). A saída é enfrentar com sobriedade esse período. O caminho oposto é aferrar-se a uma ideologia ou à figura de um Líder, deixando-se conduzir cegamente ao percurso que ele traçar.

Arendt e Benjamin, evidentemente, orientam o caminho oposto. "Caçar pérolas" não significa, portanto, saudosismo, mas ânsia por localizar, no monte de escombros da tradição, a experiência de verdade. O desenvolvimento explosivo da técnica demonstra que esta experiência passa pela compreensão do caráter destrutivo de nossa técnica: não somos capazes de controlar as forças destruidoras que nós mesmos criamos.

O que é preciso ficar claro, tanto em Benjamin quanto em Arendt, é que não se trata de olhar para o passado e tentar reconstruir uma espécie de fio da tradição que fora rompido. Não mais é possível reconstruir o traçado. Como

Mestre em Filosofia pela Universidade Estadual do Ceará - UECE. Brasileiro, residente em

Massapê-CE. E-mail: dulitle@hotmail.com

Doutor em Filosofia pela Universidade Federal do Ceará - UFC. Professor da Universidade

Estadual Vale do Acaraú - UEVA. Brasileiro, residente em Fortaleza-CE. E-mail: 
dissemos, não se pode desconsiderar a experiência da destruição, da barbárie. É preciso olhar o monte de escombros, o campo de ruínas, e se contentar com o pouco.

\begin{abstract}
Barbárie? Sim. Respondemos afirmativamente para introduzir um conceito novo e positivo de barbárie. Pois o que resulta para o bárbaro dessa pobreza de experiência? Ela o impele a partir para a frente, a começar de novo, a contentar-se com o pouco, a construir com o pouco, sem olhar nem para a direita nem para a esquerda. [...] Algumas das melhores cabeças já começaram a ajustar-se a essas coisas. Sua característica é uma desilusão radical com o século e ao mesmo tempo uma total fidelidade a esse século. (BENJAMIN, 1994).
\end{abstract}

A barbárie floresce em desenvolvimento paralelo com a técnica. A destruição é fruto de um ímpeto criativo. Sem a técnica não seria possível a carnificina dos campos de concentração, o extermínio lógica e sistematicamente articulado pelas mentes mais inventivas do século. A desilusão com o século deve redundar no que Arendt define, em Origens do totalitarismo (2012), como otimismo temerário. Frente às experiências destrutivas, que colocaram em questão o ideal de progresso, é o que temos.

\title{
CONCLUSÃO
}

Sob o pano de fundo da perda da tradição onde tudo se amontoa como num campo em ruínas, o que cabe ao filósofo? Diante das caóticas experiências políticas do século $\mathrm{XX}$, qual o seu papel?

Como fizemos perceber, não se trata de tentar reatar o fio da tradição que fora rompido. Diante do monte de escombros, Benjamin lembra-nos que é preciso contentar-se com pouco. Mais uma vez, convém lembrar, é a experiência da destruição o ponto de partida da filosofia benjaminiana. Mas a destruição é, paradoxalmente, edificante: é o que temos para começar a construir.

Tanto um pintor complexo como Paul Klee quanto um arquiteto programático como Loos rejeitam a imagem do homem tradicional, solene, nobre, adornado com todas as oferendas do passado, para dirigir-se ao contemporâneo nu, deitado como um recém-nascido nas fraudas sujas de nossa época. (BENJAMIN, 1994).

Mestre em Filosofia pela Universidade Estadual do Ceará - UECE. Brasileiro, residente em

Massapê-CE. E-mail: dulitle@hotmail.com

Doutor em Filosofia pela Universidade Federal do Ceará - UFC. Professor da Universidade

Estadual Vale do Acaraú - UEVA. Brasileiro, residente em Fortaleza-CE. E-mail: 
Diante da destruição, a metáfora do filosofar benjaminiano, como bem esclareceu Arendt, é o colecionador, visto como aquele que vasculha nas profundezas da tradição e encontra pérolas envolvidas por corais e que precisam ser salvas do monte de escombros que é a tradição em ruínas. A totalidade de experiência, tema caro para o modus philosophandi benjaminiano, passa justamente por esse mergulho nas profundezas oceânicas da tradição em declínio.

Em Arendt, é possível vislumbrar algumas alternativas. Prender-se ao niilismo entranhado na nossa sociedade pós-totalitária, que provou a crença de que tudo é possível, mesmo a transformação de homens em seres supérfluos. Negar o ultraje e aferrar-se a convicções ideológicas abstratas ou se refugiar na imagem de um Líder. Conservar um otimismo temerário. A barbárie revela 0 esfacelamento da tradição. Benjamin e Arendt alertam para o potencial destrutivo da técnica ao mesmo tempo em que evidenciam que devemos assumir a responsabilidade pelas "fraldas sujas de nossa era" e seguir em frente.

\section{REFERÊNCIAS}

ARENDT, Hannah. A condição humana. 12. ed. Rio de Janeiro: Forense Universitária, 2014.

. Homens em Tempos Sombrios. Tradução Denise Bottman. São Paulo: Companhia das Letras, 2008a.

. Compreender: formação, exilio e totalitarismo (ensaios). São Paulo: Companhia das Letras, 2008b.

ARENDT, Hannah. Entre o passado e o futuro. Trad. de Mauro W. Barbosa ET AL. Editora perspectiva: São Paulo - SP, 2001.

BENJAMIN, Andrew e OSBORNE, Peter (org). A filosofia de Walter Benjamin: destruição e experiência. Trad. Maria Luiza X. de A. Borges. - Rio de Janeiro: Jorge Zahar Ed., 1997.

. Introdução. In_ : BENJAMIN, Andrew e OSBORNE, Peter (org). A filosofia de Walter Benjamin: destruição e experiência. Trad. Maria Luiza X. de A. Borges. - Rio de Janeiro: Jorge Zahar Ed., 1997.

Mestre em Filosofia pela Universidade Estadual do Ceará - UECE. Brasileiro, residente em Massapê-CE. E-mail: dulitle@hotmail.com

Doutor em Filosofia pela Universidade Federal do Ceará - UFC. Professor da Universidade

Estadual Vale do Acaraú - UEVA. Brasileiro, residente em Fortaleza-CE. E-mail: 
BENJAMIN, Walter. Magia e técnica, arte e política: ensaios sobre literatura e história da cultura. Trad. de Sérgio Paulo Rouanet. - 7. ed. - São Paulo: Brasiliense, 1994.

$\overline{\text { Sociais). }}$.

Habermas. São Paulo: Ática, 1980. (Coleção Grandes Cientistas

ELIAS, Norbert. Os alemães: a luta pelo poder e a evolução do habitus nos séculos XIX e XX. Rio de Janeiro: Jorge Zahar, 1997.

GIDDENS, Anthony. As consequências da modernidade. São Paulo: UNESP, 1991.

LÖWY, Michael. Walter Benjamin: aviso de incêndio: uma leitura das teses "Sobre o conceito de história". São Paulo: Boitempo, 2005.

REMARQUE, Erich Maria. Nada de novo no front. São Paulo: Abril Cultural, 1981.

GAGNEBIN, Jeanne Marie. Walter Benjamin ou a história aberta. In _ :

BENJAMIN, Walter. Magia e técnica, arte e política: ensaios sobre literatura e história da cultura. Trad. de Sérgio Paulo Rouanet. - 7. ed. - São Paulo:

Brasiliense, 1994.

OSBORNE, Peter. Vitórias de pequena escala, derrotas de grande escala: a política do tempo de Walter Benjamin. . In _ : BENJAMIN, Andrew e OSBORNE, Peter (org). A filosofia de Walter Benjamin: destruição e experiência. Trad. Maria Luiza X. de A. Borges. - Rio de Janeiro: Jorge Zahar Ed., 1997.

Mestre em Filosofia pela Universidade Estadual do Ceará - UECE. Brasileiro, residente em Massapê-CE. E-mail: dulitle@hotmail.com

Doutor em Filosofia pela Universidade Federal do Ceará - UFC. Professor da Universidade

Estadual Vale do Acaraú - UEVA. Brasileiro, residente em Fortaleza-CE. E-mail: 